\title{
PARRICÍDIO À MACHADO E À HATOUM
}

TESE DE DOUTORADO

Cristiane de Mesquita Alves

cris.mesquita28@hotmail.com

Doutora em Comunicação, Linguagens e Cultura

Universidade da Amazônia (UNAMA) /Bolsista PROSUP/CAPES

Orientador: Prof. Dr. José Guilherme de Oliveira Castro

Programa de Pós-Graduação em Comunicação, Linguagens e Cultura Área de concentração: Interdisciplinar (Linguagem, Identidade e Cultura da/na Amazônia)

Data da defesa: 16 de janeiro de 2020

Palavras-chave: Parricídio; Psicanálise; Literatura Comparada.

O objetivo da tese foi compreender como se processou o Parricídio nas obras de Machado de Assis e Milton Hatoum, com base nas análises das ações e dos comportamentos dos narradores-personagens, Bento e Nael, dos romances Dom Casmurro (1899/2008) e Dois Irmãos (2000), respectivamente. A partir disso, observou-se a construção do processo de negação da paternidade em dois vieses: a morte do filho no pai, na narrativa machadiana mencionada; e a morte do pai no filho, na obra de Hatoum.

A base metodológica utilizada foi a qualitativa-interpretativa, levando em consideração os métodos propostos pelos autores Pichois e Rousseau (2011). Ambos defendem aproximações de obras literárias que se distanciam no decurso do tempo e do espaço e que apresentam traços que dialogam entre si, como temáticas semelhantes, por exemplo. Tudo isso dentro das fronteiras específicas das obras, pautadas nos discursos dos vultos e das pistas literárias que são encontrados nos textos que podem servir de análise comparativa. Outro teórico fundamental para a tese foi Remak, que relaciona "a literatura a outros campos do conhecimento e da atividade humana, especialmente os 
campos artístico e ideológico" (REMAK, 2011, p. 195), possibilitando a ampliação da análise de uma obra e a compreensão do processo criativo da mesma.

Diante dessas teorias provenientes dos estudos de Literatura Comparada, sobretudo a de Remak, que aponta "o estudo da literatura além das fronteiras [...] [definindo esta] comparação de uma literatura com outra ou outras e a comparação da literatura com outras esferas da expressão humana." (REMAK, 2011, p. 189), é que se dialogou, na investigação, os preceitos teóricos de Literatura e Psicanálise.

A Psicanálise destacou-se como a outra esfera comparativa, por entender que lidar com a análise da ficção literária já é uma forma de se envolver no universo dos fenômenos comuns, da Literatura à Psicanálise e à interpretação de textos. Ambas se correlacionam com a leitura e a compreensão do desejo, dos sentimentos recalcados, das paixões proibidas, do imaginário, do sonho "em suas múltiplas formas: ostensivas, mascaradas, reprimidas, transfiguradas, sublimadas; lida, em suma, com a intérmida fenomenologia do inconsciente e da memória, sem destacar as suas intersecções com a sua autoconsciência." (BOSI, 2014, p. 19).

Neste percurso de análises comparativas entre a Literatura e a Psicanálise, a vertente escolhida para estudo foi a de Freud, no que diz respeito ao parricídio, designado por ele como o crime principal e originário da humanidade, assim como do indivíduo. Essa teoria foi organizada com mais afinco, a partir da leitura analítica e interpretativa feita pelo psicanalista do romance de Dostoiévski, Os irmãos Karamázov ([1880]/2019), texto que se valeu para começar as reflexões da tese, junto a Totem e Tabu (2013/[1913]), intermediados por outros ensaios de Freud, que serviram de aportes para as conceituações da elaboração da presença do Complexo de Édipo ao parricídio freudiano até as considerações parricidas presentes nos romances em discussão. Ainda 
nesse âmbito, Freud (2015, p. 293-294) caracteriza o parricídio como "os mais antigos sintomas dos "ataques de morte" [que] podem então ser compreendidos como uma identificação do Eu com o pai, permitida como punição pelo supereu. Queres matar o pai, para seres tu mesmo o pai e ter direito de escolha".

Esse direito de escolha (negar o pai = matar o pai), os ataques de morte e o modo como se matou o pai e/ou o filho foram discutidos na tese como distintas formas de ações parricidas. Além de nas duas narrativas haver o sentimento de culpa que gerou uma ambivalência em relação à figura paterna, contrastam as noções de falha e falta de ter ou ser pai. Esses temas norteiam as vidas dos dois narradores-personagens, que vivem com angústias e medos frequentes, em busca de identificação. Nesse viés, tanto Bento quanto Nael vivenciam trajetórias dos "Eus" em autoterapias, que coincidem com o início da identificação "ambivalente, [que] pode tornar-se tanto expressão de ternura como desejo de eliminação." (FREUD, 2018, p. 61).

$\mathrm{Na}$ análise feita para a tese, decidiu-se compreender o porquê de as duas personagens investigadas optarem pelo desejo de eliminação, utilizando como base discussões freudianas. Ademais, buscou-se entender a formação do Eu identitário, a partir da complexa relação de Ser o pai (Bento no que concerne à paternidade de Ezequiel) e Ter o pai (Nael no tocante a ser o filho de um dos irmãos gêmeos: Omar ou Yaqub). Negar a paternidade por meio de uma ação parricida, viola o que seria um dos maiores tabus considerados pela sociedade, tornando-se o próprio tabu aquele quem mata o pai ou deseja matar o filho e vice-versa. Sendo assim, "o indivíduo que violou um tabu torna-se ele mesmo tabu, porque tem o perigoso atributo de tentar outros a seguir seu exemplo. Ele provoca inveja." (FREUD, 2013, p. 27). Partindo-se deste pressuposto, Bento e Nael, ao serem analisados como parricidas se aproximariam do Complexo de 
Édipo (sentimento de culpa ou ambivalência de sentimentos que culminariam no desejo de morte do progenitor).

Embora o parricídio freudiano tenha sua origem na análise da morte física do pai, como demonstrado no ensaio: Dostoiévski e o parricídio (1928) por Freud, defendeu-se na tese que, em Dom Casmurro e Dois Irmãos, o parricídio físico não se concretiza, de fato, apesar de Bento Santiago comemorar a morte do filho Ezequiel no final da narrativa machadiana e, em outra passagem, tentar matá-lo quando criança; e em Dois Irmãos, Nael ter reagido violentamente contra Omar, desejando vingança e afastamento de Yaqub - em uma primeira leitura do romance - o pai desejado por ele (Nael). Na tese, a partir do parricídio freudiano, alicerçou-se o parricídio literário, também chamado de parricídio simbólico e afetivo.

No decorrer da investigação notou-se que quem deseja ou comete o parricídio afetivo não considera o pai como uma figura teológica, ou seja, como uma figura sagrada. Além disso, a pessoa não se visualiza como um indivíduo capaz de proteger, criar e amar o outro. Não há salvação no ato parricida, pois tal ação se afasta do sentimento amoroso esperado entre familiares, que é capaz de perdoar, de reconstruir a vida, independente das situações adversas do presente, do passado e do futuro. O parricida afetivo não desampara ninguém, ele próprio é o desamparado. É desvinculado não somente por uma questão genética, mas se desvincula de escrever sua própria história por meio das trocas de experiências afetivas que dão sentido à vida nímia e anímica.

Concluiu-se que parricídio afetivo, portanto, é pior que o físico, uma vez que no físico, há o luto que traz certo conforto: "o afetivo é a manutenção da melancolia e do sentimento de culpa que perpetua no homem o complexo de Cronus, pois não se há o domínio ou uma certeza de quanto o tempo passa." (ALVES, 2020, p. 244-245). 
Na constituição do parricídio literário, também foi tratada a perspectiva memorialística, principalmente no emprego da memória individual e coletiva. Como aporte teórico, foram utilizados os estudos de Halbawachs (2013); de Ricoeur (2007) sobre memória, esquecimento e imaginação; de Yates (2013) acerca da elaboração de memória artificial; dentre outros. Observou-se os discursos dos dois narradorespersonagens memorialistas e a configuração de um "Eu" fragmentado e não postulado (BAUMAN, 2005). Viu-se, também, os conceitos básicos e consolidados sobre a vida e a obra dos dois autores escolhidos para análise: um canonizado (Machado de Assis) e o outro em direção ao cânone da Literatura Brasileira (Milton Hatoum). Tudo isso foi levantado na pesquisa com o intuito de compreender a existência do parricídio e de como ele foi formado nas obras Dom Casmurro, de Machado de Assis e Dois Irmãos, de Milton Hatoum.

\section{Referências}

ASSIS, Machado de. Dom Casmurro. In: Obras Completas. V. 1. 2ª ed. Rio de Janeiro: Nova Aguilar, 2008. p. 929-1225.

BAUMAN, Zygmunt. Identidade: entrevista a Benedetto Vecchi. Trad. Carlos Alberto Medeiros. Rio de Janeiro: Zahar, 2005.

BOSI, Alfredo. "Psicanálise e Crítica Literária - Proximidade e Distância”. In: PASSOS, Cleusa Rios P; ROSEMBAUM, Yudith (Orgs). Interpretações Crítica Literária e Psicanálise. São Paulo: Ateliê Editorial, 2014. p. 19-28.

DOSTOIÉVSKI, Fiádor. Os irmãos Karamázov. Trad. Herculano Villas-Boas. São Paulo: Martin Claret, 2019.

FREUD, Sigmund. Arte, Literatura e os artistas. Trad. Ernani Chaves. Obras Incompletas de Freud. Vol. 5. Belo Horizonte: Autêntica Editora, 2015.

FREUD, Sigmund. Psicologia das massas e análise do Eu e outros textos (1920-1923). Trad. Paulo César de Souza. Obras Completas V. 15. 6a reimp. São Paulo: Companhia das Letras, 2018. 
FREUD, Sigmund. Totem e Tabu. Trad. Paulo César de Souza. São Paulo: Penguim Classics Companhia das Letras, 2013.

HALBWACHS, Maurice. A memória coletiva. Trad. Beatriz Sidou. 2a ed. 7ạ reimpr. São Paulo: Centauro, 2013.

HATOUM, Milton. Dois Irmãos. São Paulo. Companhia das Letras, 2000.

PICHOIS, Claude; ROUSSEAU, André M. "Para uma definição de Literatura Comparada". Trad. Monique Balbuena. In: CARVALHAL, Tania Franco; COUTINHO, Eduardo de Faria (Orgs). Literatura Comparada: textos Fundadores. 2a ed. São Paulo: Rocco, 2011. p. 230233.

REMAK, Henry H. H. "Literatura Comparada: Definição e função". Trad. Monique Balbuena. In: CARVALHAL, Tania Franco; COUTINHO, Eduardo de Faria (Orgs). Literatura Comparada: textos Fundadores. 2ª ed. São Paulo: Rocco, 2011. p. 189-205.

RICOEUR, Paul. A memória, a história, o esquecimento. Tradução: Alain François. Campinas, SP: Editora da UNICAMP, 2007.

YATES, Frances A. A arte da Memória. Trad. Flavia Bancher. 2a reimp. Campinas, São Paulo: Editora da Unicamp, 2013.

Recebido em 02 de abril de 2020.

Aceito em 04 de maio de 2020. 